\title{
Probe into the New Thinking of Marketing Strategy of Enterprises under the Background of New Economy
}

\author{
Xingqian Yang \\ Northwest normal University Business School, Lanzhou, Gansu 730030, China. \\ yxq9998@126.com
}

\begin{abstract}
In today's society, due to rapid economic development and fierce competition in the industry, how to transform the inherent marketing model and adopt new strategic ideas to meet the competitive challenge is the dilemma faced by all enterprises today. In particular, new technologies are emerging one after another, and similar experience-based consumption concepts are frequent, subverting the inherent consumption patterns. In the context of the experience economy era, it is necessary to pay close attention to the user experience and become an inevitable choice for the enterprise marketing strategy. Fundamentally, the experiential marketing strategy is to build a new marketing strategy model based on user value. Based on this, the paper puts forward relevant countermeasures on how to adapt to the changes in the marketing environment of the economic market in the context of the new economy.
\end{abstract}

Keywords: Marketing; experiential marketing strategy; user value orientation.

\section{Introduction}

The 21 st century is an era of new economic development in the form of science and technology. This puts forward better requirements for enterprises to carry out scientific and effective production and management activities and marketing activities. The new economy has the characteristics of sustained, healthy and rapid development and has become the main direction of today's world economic development. The enterprise marketing strategy is a specific plan for the development goals of the enterprise. It is necessary to take the market economy as an important reference to promote the development of the enterprise as the basic principle. Under the new economic situation, enterprises can only adapt to the original marketing strategy. The needs of the times provide a strong guarantee for the development of the company itself.

\section{Traditional Marketing Strategy Models and Drawbacks}

The traditional marketing theory mainly includes four aspects: enterprise product, price, channel and promotion. When processing and manufacturing products, enterprises rarely adjust and innovate the product form according to the different consumer groups. The product form is relatively simple. Can only meet the basic shopping needs of consumers. The traditional marketing theory pays too much attention to the reduction of production costs. It believes that the packaging, service and cultural connotation of products are all manifestations of increasing production costs. However, according to conventional needs, the products are simply manufactured without giving any color connotation to the products. The sales channels of the products are relatively simple, and the promotion methods are often used to promote the products. There is a lack of research on the market conditions, and consumers are not the mainstay of sales. In the traditional marketing theory, it is generally believed that the purpose of marketing is to seize the market, bring more lucrative economic benefits to the enterprise, use marketing activities as the core content of the marketing strategy, and use the promotion method to achieve the purpose of broadening the marketing scope of the enterprise [1]. 


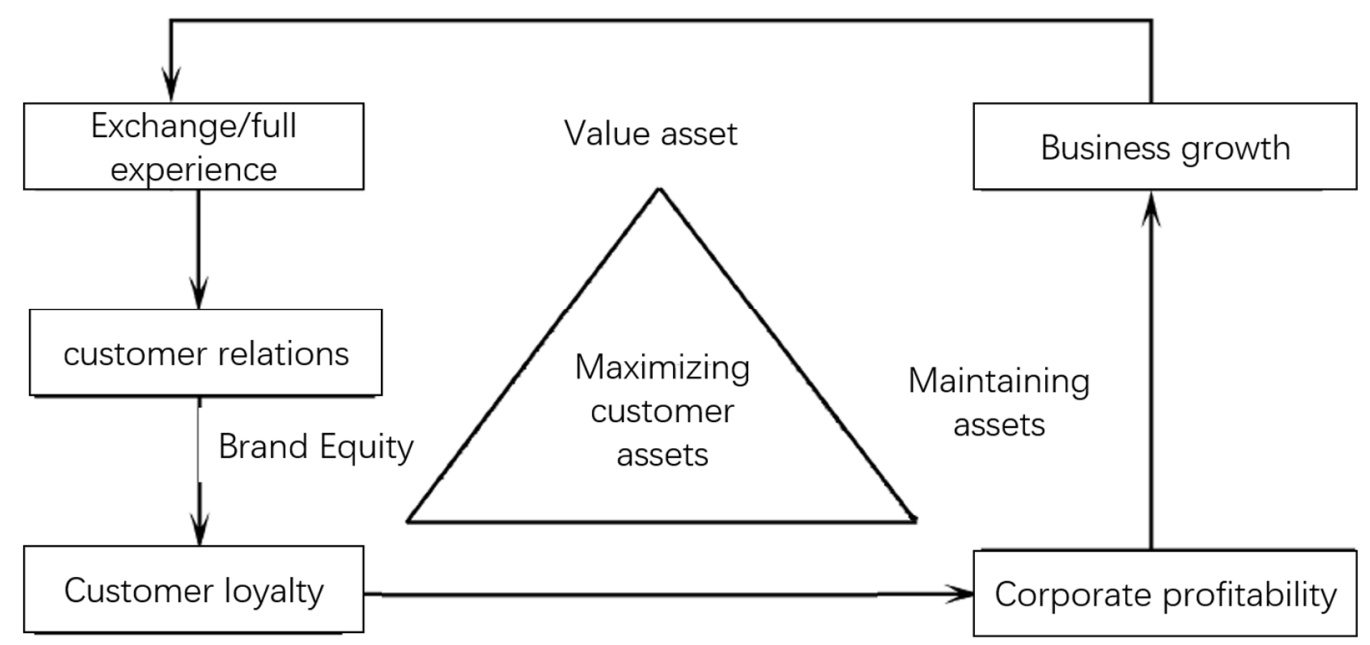

Fig 1. Strategic Program: Enterprise Marketing Behavior Logic

\section{The Impact of the New Economic Era on the Formulation of Corporate Marketing Strategies}

\subsection{Market Miniaturization}

Social development has promoted the steady improvement of the national economic level. With the continuous enhancement of people's consumption concept, new demands have been put forward in terms of consumer demand, and individuals have begun to pay attention to individual consumption. Under this circumstance, enterprise marketing must start from the perspective of consumers, determine the target group according to the direction of enterprise development, and carefully analyze the psychological characteristics of consumers on this basis, and formulate targeted consumer services for them. Consumer demand, this is the market miniaturization, is an inevitable trend of corporate marketing under the new economic background.

\subsection{Personalization of Requirements}

This is due to the increasingly fierce market competition in the context of the new economy. In the increasingly fierce market competition, the substitution of enterprise products is getting stronger and stronger, and consumers are increasingly diversified and personalized. With the continuous improvement of people's living standards and consumption levels, consumer demand is also on the rise, which requires enterprises to adopt large-scale, low-cost, high-efficiency production and through continuous research and development of new needs and models to meet More consumer needs.

\subsection{Product Diversification}

With the rapid development of society and economy, the development of technology is also changing with each passing day. In the process, many new products have emerged, which has greatly promoted the economic development of enterprises. Product upgrading not only expands the economic development space of enterprises, but also shortens the life cycle of enterprise products and greatly improves the market elimination rate of products, which will greatly affect the sustainable development of enterprises. Each product needs to go through the introduction period, development period, maturity period, and recession period. A process is needed at each stage, but once the product update speed is too fast, it is easy to cause various problems in the enterprise R\&D process. It will easily lead to inconsistent production and sales. It also marketing to the implementation of marketing strategies, which in turn hinders the actual development of the company. 


\subsection{Intense Competition}

The development of economic globalization has made the competition for enterprise development more and more fierce. If enterprises cannot seek a new development path in such fierce market competition, their economic and social benefits will be affected, even serious. It also threatens the survival of the company.

\section{Customer-Oriented Marketing Strategy in the Context of the New Economy}

\subsection{Overview of the Concept and Research Status}

With the gradual formation of the concept of experiencing consumption, the role of experience in promoting value is gradually increasing [2]. Customers can form perceptions and evaluations of value through experience and realize the experience needs of self-worth. A positive experience can give customers a sense of intimacy and trust, resulting in deep customer loyalty. This shows that customer experience is the most important driver of customer value. In the experience of marketing strategy management, Schmitt [3] research is groundbreaking. Experiential marketing is defined as "a marketing and management model driven by experience" to meet the consumer experience of marketing needs. Subsequently, with years of experience in corporate advisory practice, it proposed Strategic Experiential Modules (SMEs), including five different forms of experience, namely, the company through sensory marketing, emotional marketing, thinking marketing, action marketing and affiliate marketing. Inspire and create customer experience in these five areas, with experience media, implement an experience marketing strategy. Among them, the sensory experience is based on the five senses of sight, hearing, touch, taste and smell, creating a customer perception experience; emotional experience provides appropriate emotional stimuli by creating an appropriate scene atmosphere, inducing the inner feelings and emotions of the customer; Thinking experience is a creative way to cause customers to think about the problem, and then to achieve the problem-solving experience; the action experience is that the company adopts a diversified way to form interaction with the customer, enhance the customer experience through lifestyle and way of action; Covering the above four experiences is the experience of the customer and the ideal self, others or culture.

Tab 1. "Product-centric" and "customer-centric" differences

\begin{tabular}{|c|c|c|c|c|}
\hline $\begin{array}{c}\text { Marketing } \\
\text { concept }\end{array}$ & Leader/control & Value chain & Marketing mix elements & $\begin{array}{c}\text { Organizational } \\
\text { structure }\end{array}$ \\
\hline $\begin{array}{c}\text { Product- } \\
\text { centric }\end{array}$ & enterprise & $\begin{array}{c}\text { Assets (excluding customer } \\
\text { assets) } / \text { core capabilities } \rightarrow \\
\text { input raw materials } \rightarrow \\
\text { products / services } \rightarrow \\
\text { channels } \rightarrow \text { customer } \\
\text { transactions }\end{array}$ & $\begin{array}{c}\text { 4P: product, price, } \\
\text { distribution, promotion }\end{array}$ & $\begin{array}{c}\text { Product } \\
\text { Division } \\
\text { Division }\end{array}$ \\
\hline $\begin{array}{c}\text { take } \\
\text { customer } \\
\text { as priority }\end{array}$ & Customer & $\begin{array}{c}\text { Customer needs } \rightarrow \text { develop } \\
\text { core competence } \rightarrow \text { product } \\
\text { / service } \rightarrow \text { channel } \rightarrow \\
\text { customer relationship }\end{array}$ & $\begin{array}{c}\text { 4C: customer needs, } \\
\text { customer costs, convenience, } \\
\text { communication; 4R: } \\
\text { association, relationship, } \\
\text { response, return }\end{array}$ & $\begin{array}{c}\text { Customer } \\
\text { division } \\
\text { division }\end{array}$ \\
\hline
\end{tabular}

\subsection{Customer Experience-Oriented Marketing Strategy Model}

The core idea of experiential marketing strategy is to fully reflect the initiative of customers. Providing experience to customers or injecting experience factors into existing products/services becomes an effective means for entrepreneurs to pursue product heterogeneity. How to establish experience marketing at the enterprise level the overall framework of the strategy has gradually become a concern. Constructing a practical experiential marketing strategy model from the perspective of customer value. The model is organized around the four stages of "preparationdevelopment-implementation-control", which is carried out in time, and the evaluation feedback results formed in the strategic control phase are taken as the next step. The round enters the input 
variables of the marketing strategy preparation to form a closed loop, so that the strategic management process of experience marketing can be looped indefinitely. The details are as shown. Conclusion

In summary, in the practice of rural ecotourism management, concept innovation is an important link. As a tourism practitioner, we must pay full attention to the importance of innovation and development, and start from the perspectives of ideas, thinking, and models to enhance tourism. Develop comprehensive effects and adapt to the needs of the Internet + era. In the next step, the rural ecotourism development staff should work hard to explore, continuously draw on advanced work experience and practices, integrate into work practice, enhance the comprehensive effectiveness of development work, help rural ecotourism development, and achieve leapfrogging goals.

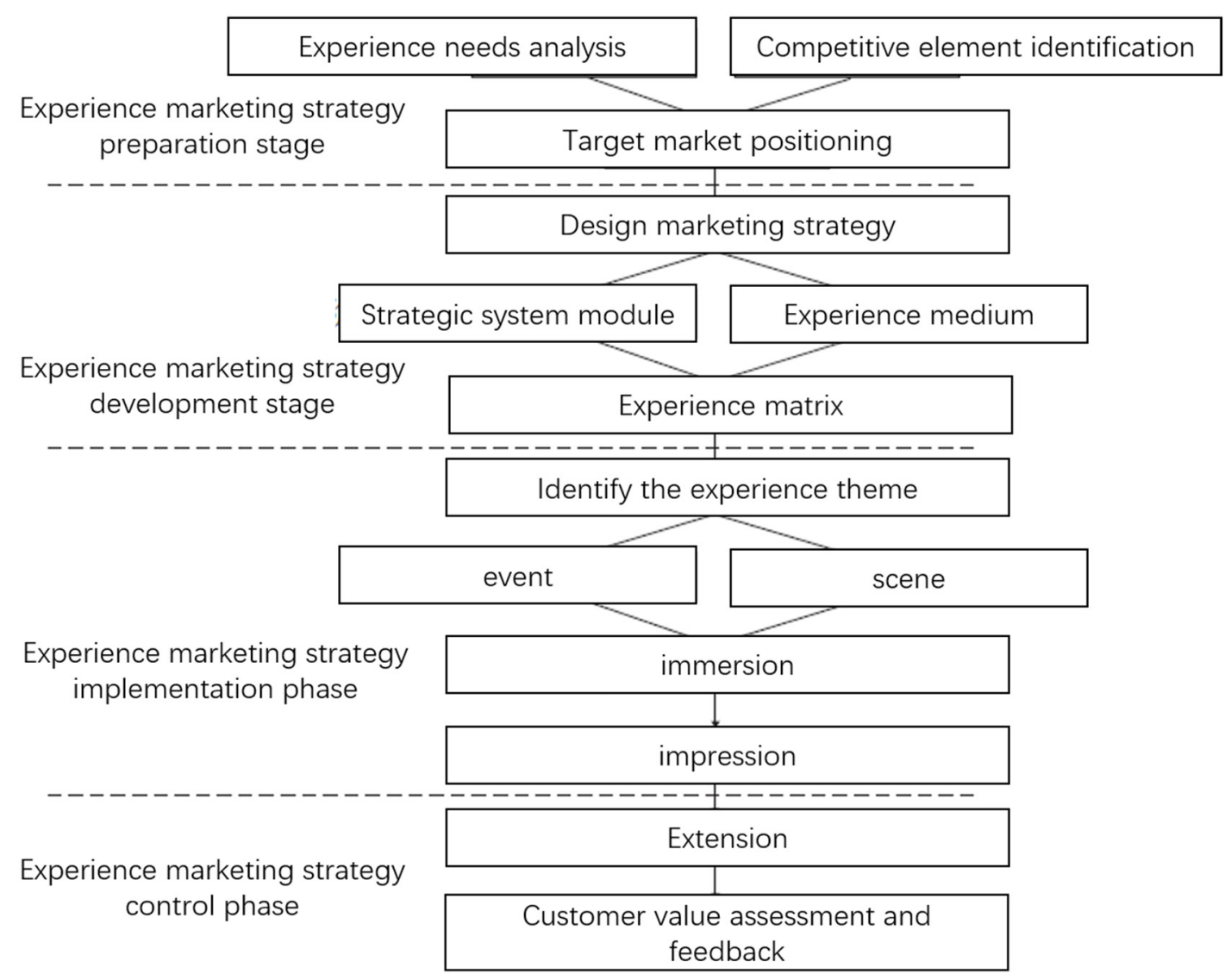

Fig 2. Overall framework of experience marketing strategy based on customer value

\subsection{Stage Implementation Method}

\subsubsection{Preparation Phase}

The purpose of in-depth analysis of customer needs is to find potential target customer segments. First, analyze the social and cultural background of the target customers and their needs and expectations in the experience. Next, analyze the relevant business environment by collecting a large amount of information, including the needs and solutions that may affect the customer experience. Finally, find the target customers. The emotional needs and clear expectations compare the differences between actual experience and experience expectations at this stage. A good understanding of customer needs and expectations can help companies use marketing strategies quickly and effectively.

\subsubsection{Development Stage}

From understanding the characteristics of the target customer group in the market segment, to understanding the entire consumer history of the target customer, including clear requirements, setting expectations, information collection, product contact, purchase and purchase recall, evaluation feedback, etc. The process of interaction between consumption and business, rationally planning and 
designing sensory elements such as sight, hearing, touch, taste and smell, integrating various factors embedded in the experience medium of people, products, processes and space environment, and exploring the true expectations of customers. Experience

\subsubsection{Implementation Phase}

Under the effective implementation of the 6E marketing mix, the company's organizational system is used to implement the marketing plan, and the experience value is transferred to the target customer to realize the customer's comprehensive consumption experience value. Through the integration of event time, space and product/service characteristics, the company introduces customers into integrated experience activities to create impressive and unforgettable themes. The company designs experience events around the theme, creates experience scenarios in interaction with customers, delivers specific brand image and other relevant information to target customers, establishes coherent customer perception, and makes experience marketing "customer-oriented". The core concept runs through.

\subsubsection{Control Phase}

In the process of formulating and implementing the program, it is particularly important to strengthen the control of the experience marketing strategy. On the one hand, the marketing plan that needs to be controlled is subject to the overall strategy of the company; on the other hand, the process of controlling the execution of the marketing plan is subject to the plan itself. Good and necessary control can ensure the smooth implementation of the strategic plan, make up for possible defects in the company's marketing plan, and ensure that the marketing plan plays its due role as much as possible. The control of the experience marketing strategy is actually the evaluation and feedback of the customer experience value, which mainly includes the evaluation of the post-experience effect and the management of the customer relationship.

\section{Conclusion}

Experiential marketing strategy is to push the traditional marketing process to the depth of the customer's mind through the experience-oriented perspective. Through strong, clear and loyal humanity speculation and value comparison, "to achieve competitive advantage and achieve the ultimate goal of market positioning" And turning this end point into a great and noble economy that extends the value of life, the movement of society and civilization*, as revealed by the \& experience value chain, by using senses, emotions, reflections, actions and connections, etc. The perspective is incorporated into environmental and market research, strategic positioning, product development, channel positioning and market positioning. "Enterprises are at a more appropriate strategic height and perspective" to introduce experience marketing into a purposeful, systematic and highly organized process. "By successful implementation of a well-designed experience marketing strategy" enables companies to "cross the long-standing communication gap between supply and demand" in a more effective way and to establish a competitive advantage in the heart of consumers." Easily realize the market positioning of its products or services" so that experience marketing can be used as a

\section{References}

[1]. Zhao Hui. Research on Marketing Strategy Based on Enterprise Life Cycle. SME Management and Technology, Vol. 1 (2017) No. 24, p. 8-12.

[2]. Chen Wei. Research on Marketing Strategy of Traditional Retail Department Stores in Ecommerce Environment. Reform and Strategy, Vol. 4 (2017) No. 21, p. 140-142.

[3]. Jiang Hao, Wang Xue, Ren Jie. On the Transformation of Marketing Strategy in the Age of Network Economy. Inner Mongolia Coal Economy, . Vol. 8 (2016) No. 28, p. 46-47.

[4]. Hu Chaoju. Thoughts on the Marketing Strategy of Chinese Commercial Banks under the Condition of Globalization Reform and Strategy, Vol. 4(2012) No. 24, p. 74-77. 
[5]. Wang Qihe. Reanalysis of Enterprise Marketing Strategy and New Connotation of Marketing Strategy under the Background of Big Data. Statistics and Decision, Vol.1 (2014) No. 20, p. 198201.

[6]. Liu Fengjun, Lei Bingzhen, Wang Yanxia. Consumer Demand and Marketing Strategy in the Age of Experience Economy. China Industrial Economy, Vol.8 (2002) No. 32, p. 81-86.

[7]. Liu Tie, Li Guihua, Lu Hongliang. The Influence Mechanism of Online and Offline Integrated Marketing Strategies on Online Retail Brand Experience. China Circulation Economy, Vol.11 (2014) No. 32, p. 51-57. 